\title{
Limitations to the Therapeutic Potential of Tyrosine Kinase Inhibitors and Alternative Therapies for Kidney Cancer
}

\author{
Hossam Kamli, MSc, ${ }^{1,2}$ Li Li, MD, PhD, ${ }^{3,4}$ Glenda C. Gobe, MSc, PhD ${ }^{1,5}$ \\ ${ }^{1}$ The University of Queensland Princess Alexandra Hospital Kidney Disease Research Collaborative, Translational Research Institute, \\ Brisbane, Queensland, Australia ${ }^{2}$ Department of Clinical Laboratory Sciences, College of Applied Medical Sciences, King Khalid University, \\ Abha, Saudi Arabia ${ }^{3}$ The University of Queensland Faculty of Medicine, Ochsner Clinical School, New Orleans, LA ${ }^{4}$ Institute of Translational \\ Research, Ochsner Clinic Foundation, New Orleans, LA ${ }^{5}$ The University of Queensland National Health and Medical Research Council \\ Chronic Kidney Disease, Queensland Centre for Research Excellence, Royal Brisbane and Women's Hospital, Brisbane, Australia
}

\begin{abstract}
Background: Renal cell carcinomas (RCCs) are the most common primary renal tumor. RCCs have a high rate of metastasis and have the highest mortality rate of all genitourinary cancers. They are often diagnosed late when metastases have developed, and these metastases are difficult to treat successfully. Since 2006, the standard first-line treatment for patients with metastatic RCC has been multitargeted tyrosine kinase inhibitors (TKIs) that include mammalian target of rapamycin (mTOR) inhibitors. RCCs are highly vascularized tumors, and their angiogenesis is controlled by tyrosine kinases that play a vital role in growth factor signaling to stimulate this process. TKI therapy was introduced for direct targeting of angiogenesis in RCC. TKIs have been moderately successful in the treatment of metastatic RCC and initially increased cancer-specific survival times. However, RCC rapidly becomes resistant to TKIs, and no current drug has produced a cure for advanced RCC.

Methods: We provide an overview of RCC, explain some reasons for therapy resistance in RCC, and describe some therapies that may overcome resistance to TKIs. The key pathways that determine therapy resistance are illustrated.

Results: Factors involved in the development and progression of RCC include genetic mutations, activation of hypoxia-inducible factor and related proteins, cellular metabolism, the tumor microenvironment, and growth factors and their receptors. Resistance to the therapeutic potential of TKIs can be acquired or intrinsic. Alternative therapies include other small molecule drugs and immunotherapy based on immune checkpoint blockade.

Conclusion: The treatment of RCC is undergoing a paradigm shift from sole use of small molecule antiangiogenesis TKIs as firstline therapy to include newly approved agents for second-line and third-line therapy that now involve the mTOR pathway and immune checkpoint blockade drugs for patients with advanced RCC.
\end{abstract}

Keywords: Angiogenesis, carcinoma-renal cell, drug resistance, enzyme inhibitors, immunotherapy, protein kinase inhibitors

Address correspondence to Glenda Gobe, MSc, PhD, Kidney Disease Research Collaborative, The University of Queensland Faculty of Medicine, Translational Research Institute, 37 Kent Street, Woolloongabba, Queensland 4102, Australia. Tel: +61-7-3443-8011. Email: g.gobe@uq.edu.au

\section{INTRODUCTION}

Renal cell carcinomas (RCCs) are the most common kidney neoplasms and the ninth most common malignancy worldwide, representing $2 \%-4 \%$ of all types of cancers. ${ }^{1}$ For primary kidney neoplasms, surgical ablation is the standard management, usually via radical or partial nephrectomy. Although these procedures successfully remove the primary neoplasm, the reduced kidney mass is associated with significant risk of adverse functional outcomes, such as chronic kidney disease. One of the main problems for detection of a kidney cancer is that the primary lesion is often masked by functional compensation of the healthy kidney. Many patients with RCC are diagnosed late when metastases have developed. These metastases are difficult to treat. Until the mid-2000s, cytokine-based therapy (interleukin-2 [IL-2] and interferon alpha [IFN- $\alpha$ ]), which had an approximately $10 \%$ response rate, was the standard of care for metastatic RCC..$^{2-4}$ Since 2006, targeted therapeutics have replaced cytokine therapy and include tyrosine kinase inhibitors (TKIs) (sunitinib, sorafenib, pazopanib, and axitinib), mammalian target of rapamycin (mTOR) inhibitors (everolimus and temsirolimus), and angiogenesis/vascular endothelial growth factor (VEGF) inhibitors (bevacizumab). ${ }^{2-5}$ These therapies have been moderately successful in the treatment of metastatic RCC, but a significant problem for patients with RCC is the development of resistance to cancer therapy.

Most resistance mechanisms are biologically mediated, such as by alteration of the target gene itself or by activation of bypass pathways. ${ }^{5}$ Pharmacologic resistance 
mechanisms involve poor penetration of the drug or activation of cellular pumps that drive the drug from the cell. Some mechanisms of resistance involve phenotypic transformations such as epithelial-mesenchymal transition (EMT). ${ }^{6}$ In this review, we provide an overview of RCC, explain some reasons for therapy resistance in $\mathrm{RCC}$, and describe some therapies that may overcome resistance to TKIs.

\section{RENAL CELL CARCINOMA}

RCC is a dangerous cancer with significant mortality. The highest rates of kidney cancer incidence (in 2012, 338,000 new cases, $2.4 \%$ of the world total) were estimated in North America, Australia/New Zealand, and Europe, where rates were $>10$ per 100,000 in males and $>5$ per 100,000 in females. $^{7,8}$ Incidence rates were lowest $(<1.5$ per 100,000$)$ in Africa and the Pacific Islands. ${ }^{9}$ Of the 144,000 deaths from kidney cancer (1.7\% of all deaths) estimated in 2012, 75,000 (52\%) were in more developed global regions. Males have approximately double the chance of developing RCC compared with females. ${ }^{8}$ The RCC incidence rate is associated with a number of factors such as obesity, hypertension, smoking, chronic use of pain medications, exposure to certain chemicals such as trichloroethylene, and genetic factors such as Von Hippel-Lindau (VHL) syndrome and BirtHogg-Dubé syndrome. ${ }^{9}$ Early research placed emphasis on the genetic and molecular pathways of RCC as a consequence of VHL mutation or inactivation, especially in clear cell RCC (ccRCC).

At least 16 subtypes of RCC have been described, as well as some common benign renal neoplasms such as renal oncocytoma. ${ }^{10-12}$ The most common and consequently the most researched subtype is ccRCC, accounting for approximately $70 \%$ of RCC. Patients with ccRCC have an overall 5year survival rate of $70 \%-80 \% .{ }^{11,12}$ Papillary RCC is the second most common subtype, comprising 15\%-20\% of RCC, and has an overall 5-year survival rate of $80 \%-90 \% .{ }^{12}$ Chromophobe RCC accounts for $6 \%-11 \%$ of cases, with the best prognosis of 5 -year survival at approximately $90 \% .{ }^{12} \mathrm{Col}-$ lecting duct $\mathrm{RCC}$ is a rare subtype, accounting for $<1 \%$ of all RCC, but it has the worst prognosis, with a 5-year survival rate $<5 \%$. $^{12}$ The remaining subtypes occur very rarely.

\section{FACTORS IN DEVELOPMENT AND PROGRESSION OF RENAL CELL CARCINOMA AND POTENTIAL TREATMENT TARGETS Genetic Mutations}

Genetic alterations are common in RCC. Typically, there is a loss of tumor suppressor gene function either by deletion of the gene or hypermethylation of the gene promoter. Almost all hereditary and $86 \%$ of sporadic ccRCC cases have these mutations, particularly in the VHL gene that encodes the VHL protein (pVHL). ${ }^{13}$ Loss or alteration of the VHL gene leads to the abnormal accumulation of hypoxia-inducible factor (HIF) proteins and subsequent activation of HIF target genes that are central to controlling angiogenesis. ${ }^{14}$ Other tumor suppressor genes - such as the Wilms tumor 1 gene (WT1), the phosphatase and tensin homolog (PTEN) deleted on chromosome 10 gene, and p53-are all involved in activation of the apoptotic pathway that involves disruption of the cell cycle and progression of RCC. ${ }^{15,16}$ WT1 is responsible for the regulation of downstream targets that are involved in proliferation and cell migration and in vessel formation via the inhibition of VEGF and angiopoietin (Ang). ${ }^{15}$ Low WT1 transcript levels have been reported in RCC tissue samples compared with noncancerous kidney tissue, demonstrating the importance of loss of this gene in RCC development. Similarly, PTEN expression is frequently reduced in advanced RCC. $^{16}$

One of the most commonly mutated or inactivated tumor suppressor genes in cancer is p53; however, there is wide variation in the reported incidence and significance of p53 mutations in patients with RCC. ${ }^{17}$ In some cases, p53 mutations were seen as prognostic factors for RCC, with an increased incidence of p53 mutations related to increasing grade and stage of the $\mathrm{RCC}^{17}$ and increased p53 expression correlating with reduced disease-specific survival. ${ }^{18}$ In other cases, p53-independent cell cycle inhibitors, such as the cyclin-dependent kinase inhibitor p27, regulated the cell cycle at the G1 checkpoint and mediated oncogenic signaling pathways in RCC, including the phosphoinositide 3-kinase (PI3K)/Akt pathway, cyclin D1, and c-Myc. ${ }^{19}$

\section{Activation of Hypoxia-Inducible Factors and Related Proteins}

Increased cell cycle activity and proliferation in RCC consume energy and reduce oxygen supply, leading to increased angiogenesis and metabolic bypass in the tumor microenvironment. HIFs regulate and augment angiogenic growth factor production, which in turn increases oxygen delivery and metabolic reprogramming of cellular glucose and energy metabolism. ${ }^{20}$ Under normal conditions, when tissue oxygen levels are adequate, HIFs are rapidly degraded via pVHL-mediated ubiquitination. HIF $\alpha$, a member of the HIF family, is notable for its expression in RCC cells. In the presence of oxygen, HIF $\alpha$ is hydroxylated, resulting in a binding site for $\mathrm{pVHL}$. In a hypoxic setting or in cells that lack $\mathrm{pVHL}, \mathrm{HIF} \alpha$ is involved in RCC progression by altering the regulation of target genes that are responsible for changes that take place in RCC metabolism and by promoting the proliferation and angiogenesis that are characteristic of RCC tumors. ${ }^{20,21}$ Three human HIF $\alpha$ dimers have been described; however, the HIF1 $\alpha$ and HIF2 $\alpha$ subunits have been most frequently reported in RCC. The transcriptional activator HIF2 $\alpha$ plays a critical role in renal tumorigenesis through its potentiating effect on the c-Myc oncogene. ${ }^{21}$ The HIF $\alpha$ dimers and their associations with pVHL and angiogenic and tumorigenic growth factors represent key potential targets for therapy in patients with RCC. ${ }^{22}$

\section{Cellular Metabolism}

RCCs are highly metabolic cancers. ${ }^{23}$ The increased energy demand of proliferating tumor cells, accompanied by the promotion of angiogenesis, drives increased oxygen levels within the tumor itself. ${ }^{24}$ However, RCC cells do not produce energy in the form of adenosine triphosphate (ATP) in the same way that noncancerous renal tissue does. RCCs and other cancers are highly dependent on aerobic glycolysis for the production of energy; this phenomenon is well established in RCC and is called the Warburg effect. ${ }^{25,26}$ Additionally, hypoxia in cancer cells is accompanied by an increased efflux of protons, with upregulation of the carbonic anhydrase IX (CAIX) transmembrane protein that allows tumor cells to survive despite disturbances in the acid-base chemistry of the tumor microenvironment. ${ }^{27}$ 


\section{Tumor Microenvironment}

Additional extracellular support by the tumor microenvironment is essential for RCC proliferation and progression. ${ }^{6}$ Although the human immune system has a natural capability to inhibit tumor cell growth and to eradicate cancer cells, in many cases, the immune cells seem to have a secondary role of stimulating cancer growth and invasiveness. The immune cell population is typically made up of $T$ cells, B cells, dendritic cells, natural killer cells, monocytes/macrophages, and neutrophils. ${ }^{28}$ RCC growth is associated with impaired antitumor immune response, ensuring sustained proangiogenic, proproliferative, and antiapoptotic stimulation. ${ }^{29} \mathrm{Sev}-$ eral known factors - such as the extracellular matrix metalloproteinase (MMP)-2 and MMP-9, the epithelial cell adhesion molecule (EpCAM), and members of the integrin/cadherin family-have the capacity to catalyze the tissue protective barriers. When these extracellular matrix proteins are disturbed, RCC invasion is more likely to occur. ${ }^{29,30}$ These data suggest that cancer-related immunity and inflammation are reasonable targets for therapy. In addition, the presence of the inflammatory mediators locally in the tumor microenvironment can be a useful tool for risk predictions in patients with RCC. ${ }^{31,32}$

\section{Growth Factors, Their Receptors, and Downstream Targets}

The tumor development and cellular proliferation that take place in RCC can be attributed to a disequilibrium among growth factors and growth factor receptors that ultimately promotes the development of RCC. ${ }^{33}$ Tumor angiogenesis is of particular importance in RCC, with several proangiogenic growth factors, such as VEGF and platelet-derived growth factor (PDGF), being overexpressed in RCC. These proangiogenic growth factors are expressed on different sites, with VEGF receptors (VEGFR) on the endothelial cells of the tumor vessels and PDGF receptors (PDGFR) present in vascular pericytes. ${ }^{34}$ The pericyte-covered tumor blood vessels resist inhibition of VEGF by alternative stimulation of endothelial cell survival signals. ${ }^{35}$ Receptor pathways for Ang-1/2 and tyrosine kinase with immunoglobulin-like and EGF-like domains 2 (Tie2) are other promising angiogenic treatment targets considered to be beyond VEGF/PDGF regulation in RCC. Ang-2 is strongly expressed in the vascular endothelium of both noncancerous kidneys and RCC but weakly expressed in tumor cells. Tie2, on the other hand, is exclusively expressed on the endothelium. ${ }^{36}$

The mTOR gene is another important potential therapy target. ${ }^{37}$ Its significant role in cellular bioenergetics and cell proliferation makes it a prime target for therapeutic development in RCC. ${ }^{37} \mathrm{mTOR}$ is a kinase in the family of PI3K-related kinases, and it is activated via growth factor or cytokine receptors located on the cell surface. ${ }^{38}$ mTOR consists of two complexes: mTORC1 and mTORC2. mTORC1 contains the co-protein regulatory-associated protein of TOR (RAPTOR), which is sensitive to rapamycin, and mTORC2 contains its rapamycin-insensitive companion RICTOR. ${ }^{38}$ $\mathrm{PI} 3 \mathrm{~K}$ is also important, as it phosphorylates and activates Akt, which is responsible for the activation of tuberin, also known as the tuberous sclerosis protein complex 2 (TSC2). TSC2 together with hamartin (also called TSC1) forms the TSC1/TSC2 complex. ${ }^{38}$ mTOR is phosphorylated as a result of the consecutive loss of TSC1 and TSC2. Phosphorylated
mTOR is then responsible for the stimulation of energy and protein synthesis in RCC. In addition, inhibition of glycogen synthase kinase 3 (GSK-3) activates mTOR. ${ }^{38}$

The $W n t / \beta$-catenin signaling cascade has emerged as having an important role in the development and progression of RCC. ${ }^{39}$ The secreted Wnt glycoprotein activates this pathway, which results in the cytoplasmic accumulation of $\beta$-catenin that later translocates to the nucleus where it interacts with the pVHL/HIF axis and activates RCC target genes. ${ }^{40}$ These signaling cascades not only support cancer growth but are also equally important for delivering sufficient nutrients and oxygen in tumorigenesis and beyond. ${ }^{41}$

\section{MOLECULAR MECHANISMS OF THERAPY RESISTANCE IN RENAL CELL CARCINOMA}

Generally, tumors are considered to be sensitive to targeted agents if their growth and proliferation are dependent on the signaling pathway targeted by these agents. Inaccessibility of a drug to its target may result from structural alterations or activation of alternative signaling pathways. Alternatively, drug-mediated inhibition may be counterbalanced by upregulation of a separate set of molecules. ${ }^{42}$ Alterations in the molecular pathways establish resistance against a specific targeted therapy. In RCC treatment, the drug exposure-dependent origin of resistance has been established in both preclinical and clinical studies. ${ }^{43}$ Tumor resistance to antiangiogenic therapies has been categorized into two models: acquired (evasive) and intrinsic (preexisting) resistance. ${ }^{44,45}$ Table 1 compares acquired and intrinsic therapy resistance. , $34,35,44,46-68$ Figure 1 demonstrates essential differences between intrinsic and acquired resistance. Figure 2 demonstrates molecular mechanisms of resistance to therapy in RCC.

\section{Acquired (Evasive) Resistance and Intrinsic (Preexisting) Nonresponsiveness}

Emerging research suggests that at least 5 distinct processes mediate acquired resistance to VEGF-targeted therapies: (1) upregulation or downregulation of alternative signaling pathway genes that support tumor angiogenesis via the angiogenic switch; (2) increased pericyte accumulation and activity around tumor vessels; (3) recruitment of proangiogenic inflammatory cells from bone marrow; (4) lysosomal sequestration of drugs; and (5) increased invasiveness of tumor cells via EMT, negating the need for neovascularization. ${ }^{44,45}$ Gotink et al were first to postulate on the mechanism of lysosomal sequestration as a specific cellular adaptation to toxic TKI concentrations in in vitro models. ${ }^{46}$ These mechanisms are described below with examples that explain acquired resistance to TKI and mTOR inhibitors.

Intrinsic nonresponsiveness to cancer therapy is a preexisting condition, perhaps genetically determined, that can be defined by the minimal or absent beneficial effect of a cancer therapy, ranging from the inability to shrink or stabilize tumors to the lack of improvement in quality of life. ${ }^{47}$ In RCC, one genetic determinant of nonresponsiveness may be, at least in part, expression of the multidrug resistance 1 (MDR-1) gene. However, studies using appropriate pharmacologic intervention to reverse multidrug resistance and make RCC more sensitive to chemotherapy have, in general, been disappointing. ${ }^{48}$ Complete 


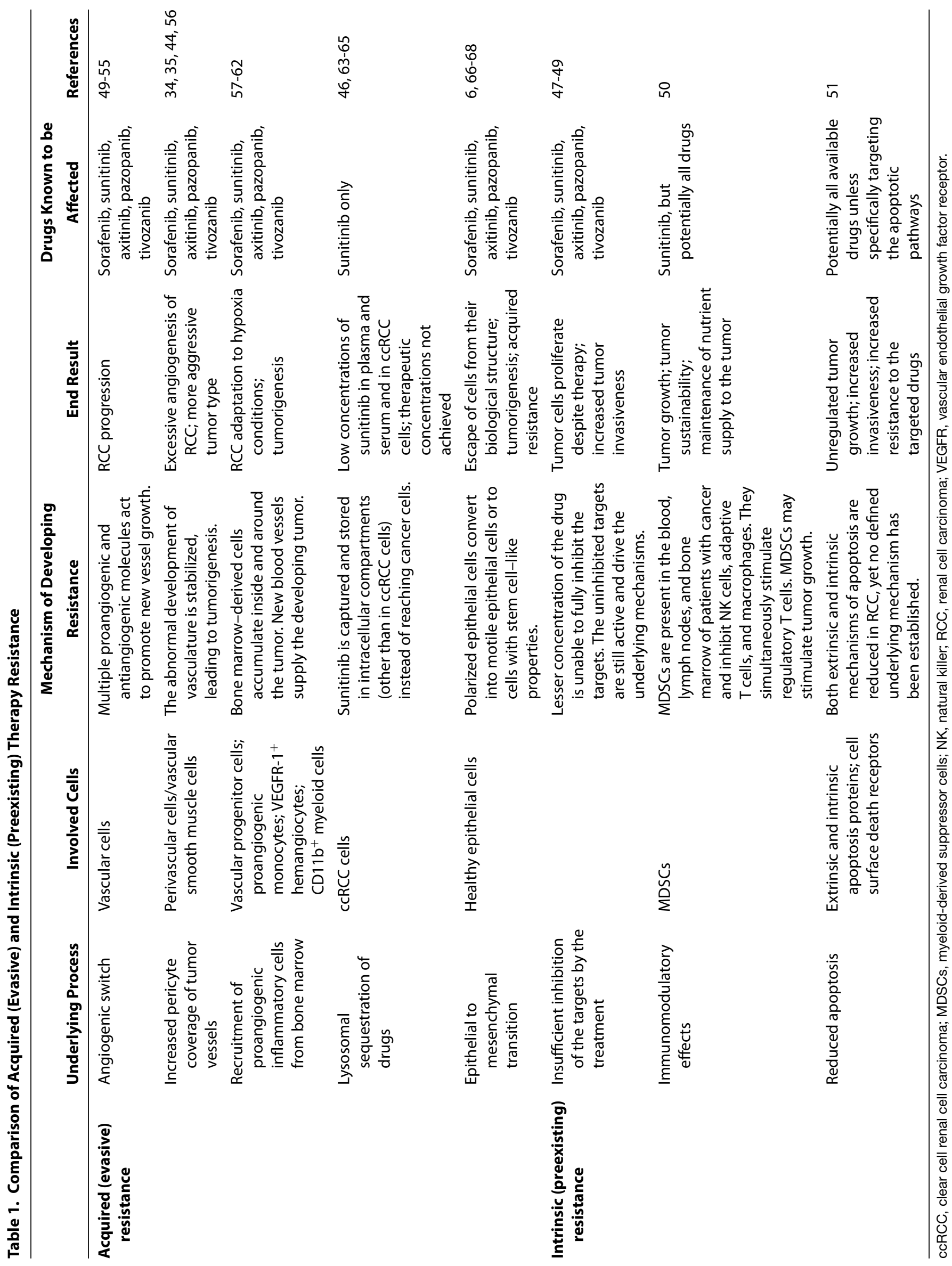



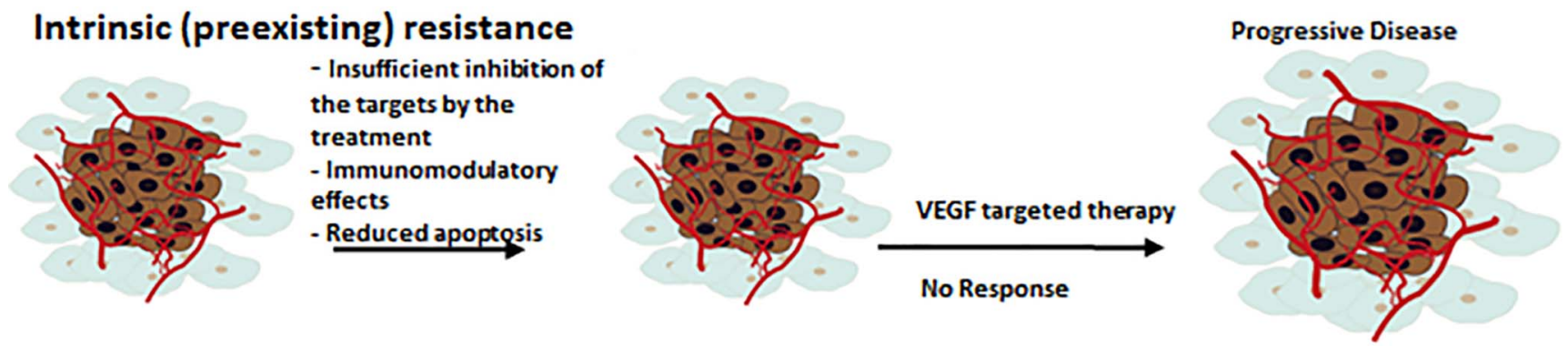

\section{Acquired (evasive) resistance}
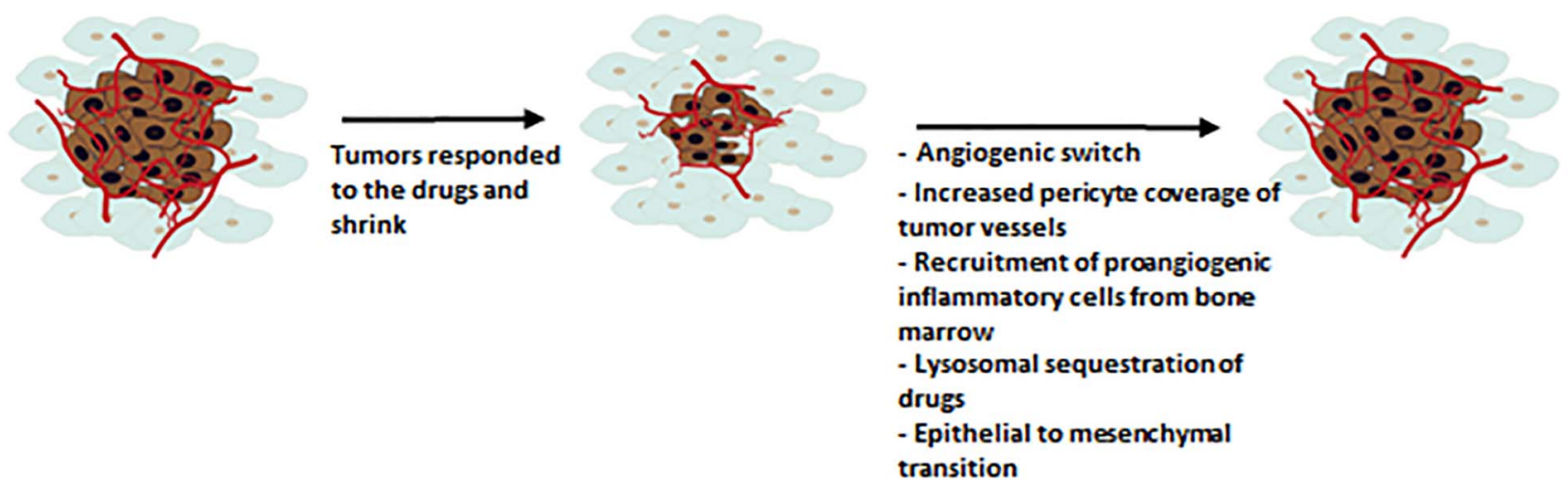

Figure 1. Possible pathways of resistance to targeted therapies that potentiate tumor aggressiveness in renal cell carcinoma. The mechanisms for intrinsic (preexisting) resistance or nonresponsiveness involve (1) insufficient inhibition of the targets by the treatment, (2) immunomodulatory effects, and (3) reduced apoptosis. In acquired (evasive) resistance, the tumor initially responds to therapy but stops responding to the treatment after initial shrinkage, and the disease relapses. The pathways postulated to be involved in acquired resistance are (1) an angiogenic switch, (2) increased pericyte coverage of tumor vessels, (3) recruitment of proangiogenic inflammatory cells from bone marrow, (4) lysosomal sequestration, and (5) epithelialmesenchymal transition. VEGF, vascular endothelial growth factor.

nonresponsiveness of patients to VEGF-targeted therapy also indicates that this condition is likely to be determined by individual genetic determinants. Moreover, the primary resistance in some patients could be relative, determined by the individual pharmacokinetic variability and/or VEGFR polymorphisms. ${ }^{47}$

\section{Alternative Angiogenic Pathways}

Tumor responsiveness to TKls followed by lack of response with restored tumor growth is commonly seen clinically in patients with RCC. Preclinical studies have provided much of our current knowledge. For example, the central tumor promotion process of angiogenesis may occur through overexpression of factors involved in alternative proangiogenic pathways and by downregulation of angiostatic ones. ${ }^{49}$ Casanovas et al studied genetically engineered Rip1-Tag2 mice in a preclinical model of pancreatic neuroendocrine (islet cell) cancer. ${ }^{50}$ They performed DC101 antibody-mediated blockade of the VEGF signaling pathway (VEGFR2 in particular) and generated 10-14 days of transient attenuation of tumor growth with an associated decrease in tumor vascularity. Following tumor regrowth and revascularization, mRNA analysis revealed that the new tissue contained overexpression of proangiogenic factors, notably fibroblast growth factor 1 and 2 (FGF1/2), ephrin A1 and A2
(EFNA1/2), and Ang-1, compared with tumor tissues that had not been treated. The upregulation of these genes is likely the result of acute hypoxia caused by antiangiogenic treatments. ${ }^{50}$

Another factor that plays a significant role in RCC angiogenesis is IL-8. Mizukami et al first described the use of anti-IL-8 antibodies to block tumor angiogenesis in colon cancer cell lines. ${ }^{51}$ In the same study, cell lines with $\mathrm{HIF} 1 \alpha$ knockdown were shown to preserve VEGF expression. Other studies investigating the ability of IL-8 to function as a proangiogenic cytokine have demonstrated that antibodymediated neutralization of IL-8 caused tumor resensitization to sunitinib treatment. ${ }^{52}$ The link between IL-8 and sunitinib resistance suggests that IL- 8 levels may be used as a surrogate for predicting response to sunitinib and may identify patients with acquired or intrinsic resistance to sunitinib. ${ }^{52}$

The Ang/Tie signaling system is another essential proangiogenesis pathway in RCC that acts alongside VEGF to promote vascularization of RCC by moderating endothelial cell survival and vascular maturation. ${ }^{53,54}$ The Ang/Tie pathway is composed of tyrosine kinase receptors Tie1 and Tie2 with corresponding Ang-1 and Ang-2 specific ligands. The study by Wang et al demonstrated that plasma levels of Ang-2 decreased during the 


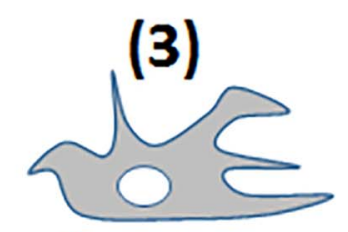

Tumor stroma/fibroblast

PDGF-C

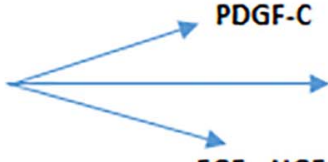

\section{SDF1 \\ IL-8}

FGF HGF

G-CSF
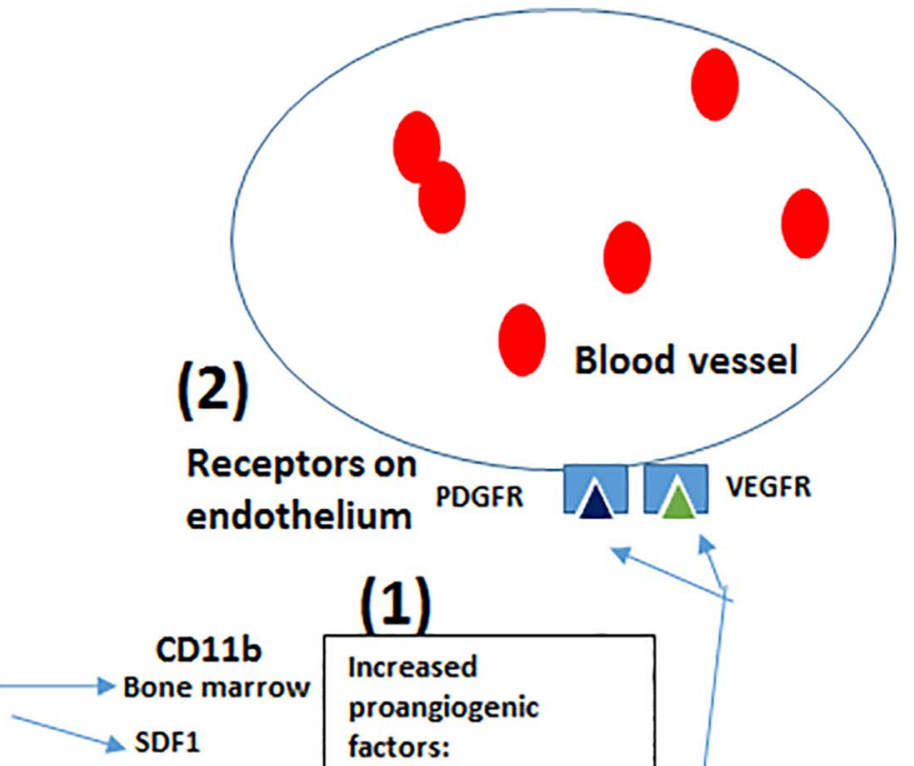

(1)

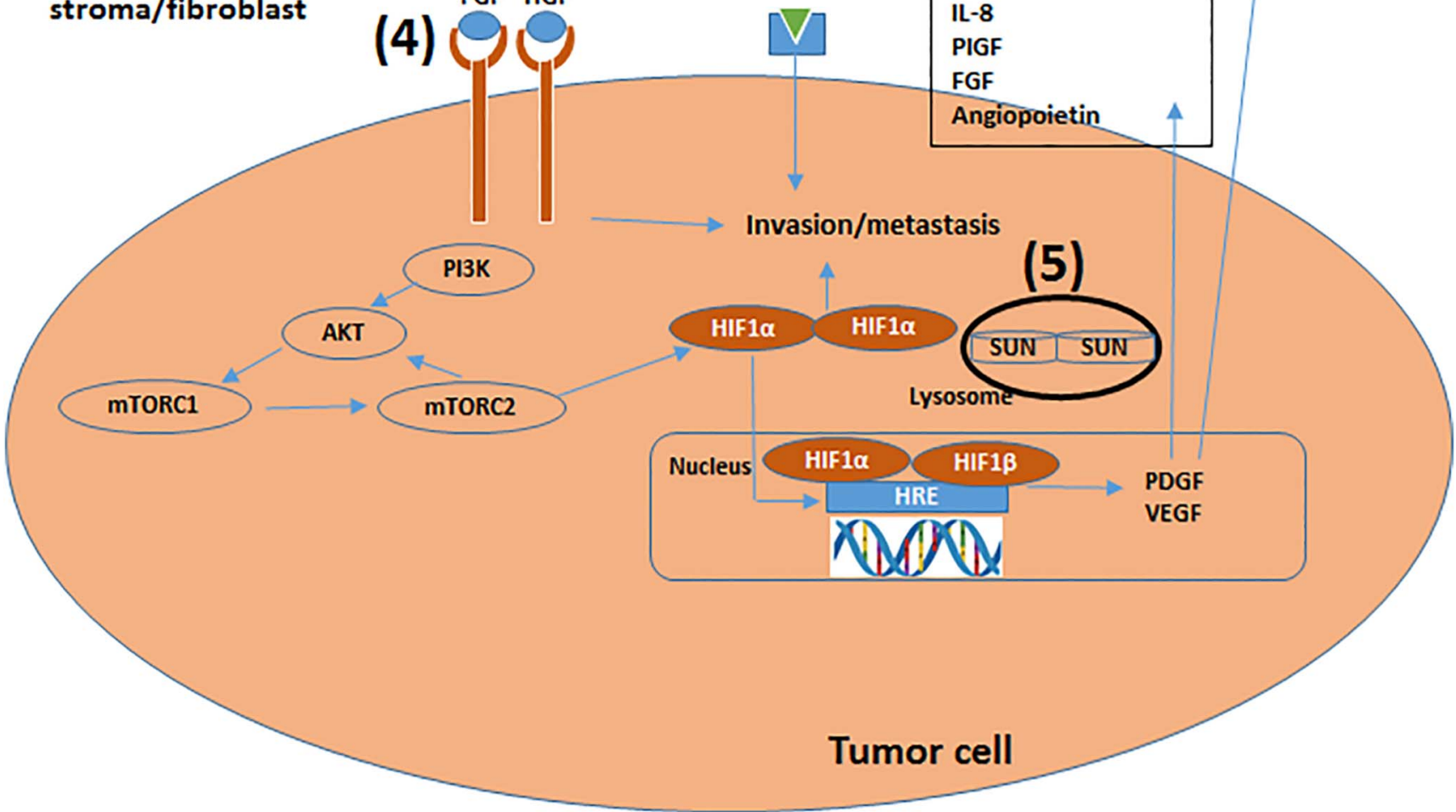

Figure 2. Potential mechanisms of resistance to sunitinib in renal cell carcinoma (RCC) may include (1) upregulation of proangiogenic factors (IL-8, PIGF, FGF, angiopoietin), (2) increased invasive and metastatic potential of the tumor, (3) resistance mediated by the tumor microenvironment through the recruitment of bone marrow-derived cells (CD11b), (4) secretion of FGF and HGF and activation of alternative signaling pathways, and (5) lysosomal sequestering of sunitinib. G-CSF, granulocyte-colony stimulating factor; HGF, hepatocyte growth factor; HIF $1 \alpha / \beta$, hypoxia-inducible factor 1 alpha/beta; HRE, hypoxia-responsive element; IL, interleukin; mTORC1 and mTORC2, mammalian target of rapamycin complex 1 and 2; PDGF(R), platelet-derived growth factor (receptor); PDGF-C, platelet-derived growth factor-C; PIGF, placental growth factor; PI3K, phosphoinositide 3-kinase; SDF1, stromal cell-derived factor 1; SUN, sunitinib; VEGF(R), vascular endothelial growth factor (receptor).

responsive stage of sunitinib therapy and increased during the sunitinib resistance phase in patients with metastatic RCC..$^{53}$ Ang-2/Tie2 signaling is likely to act alongside the VEGF-dependent pathway. Therapies that aim to target
Ang-2 by a new class of biotherapeutics called CovX-Bodies (a protein-antibody construct) demonstrate decreased tumor vessel density, especially when these drugs are combined with sunitinib and sorafenib. ${ }^{55}$ 


\section{Pericyte Coverage of Tumor Vessels}

VEGF and other factors are expressed in considerable levels by the pericytes to support endothelial cells. ${ }^{34,35}$ During anti-VEGF therapy, pericytes are responsible for the integrity of stable and functioning blood vessels in some tumors. Several groups have observed that pericytes covering the tumor vessels survive cancer therapy. ${ }^{44}$ Thus, pericytes appear to be critical for maintaining the structure of tumor vasculature in the absence of VEGF-mediated signaling. Moreover, anti-VEGF therapy is more potent in tumors that lack pericyte protective coverage. ${ }^{34,35}$ Sunitinib and sorafenib target both VEGFR and PDGFR and result in the inhibition of PDGFmediated pericyte induction. ${ }^{56}$ Such pericyte inhibition may add to tumor metastasis by disrupting vascular integrity and releasing the tumor cells into the bloodstream. ${ }^{56}$

\section{Bone Marrow-Derived Proangiogenic Inflammatory Cell Recruitment}

Antiangiogenic treatment not only causes regression of tumor vasculature but also causes hypoxia, which stimulates proangiogenic factor production in the tumor and recruitment of different bone marrow-derived cells (BMDCs). These BMDCs include proangiogenic tumor-associated macrophages, ${ }^{57}$ VEGFR1-positive hemangiocytes, ${ }^{58}$ immature monocytes (Tie-positive monocytes), ${ }^{59}$ and CD11b-positive myeloid-derived suppressor cells. ${ }^{60}$ BMDCs act primarily through the expression of cytokines, growth factors, and proteases, supporting the remodeling of vasculature. ${ }^{61}$ The immunosuppressive and proangiogenic nature of myeloidderived suppressor cells indicates that they might have a role in the development of therapy resistance in patients treated with sunitinib. ${ }^{62}$

\section{Sunitinib Sequestration in Lysosomes}

For many years, sunitinib has been the cornerstone of TKI therapy for RCCs and central to the study of their therapy resistance. Resistance to sunitinib therapy may be via lysosomal sequestration of the drug. ${ }^{63}$ The intratumoral concentration of sunitinib may be up to 10 times higher than the plasma level. Sunitinib sequestration to lysosomes may then deplete the cellular concentration in tumor cells. ${ }^{64}$ Lysosomal sequestration was confirmed by using fluorescent tagging and microscopy. The hydrophobic nature of sunitinib facilitates crossing the lysosomal membrane. However, protonation in acidic lysosomes traps it inside the lysosomes. Lysosomal sequestration of sunitinib is, however, considered to be reversible. ${ }^{64,65}$

\section{Tumor Cell Invasiveness via \\ Epithelial-Mesenchymal Transition}

Increased tumor invasiveness contributes to tumor adaptation to antiangiogenic therapy. Increased tumor invasiveness and slow tumor growth were observed in a preclinical mouse model of glioblastoma despite downregulated VEGF, HIF $\alpha$, and MMP-9. ${ }^{66}$ Hammers et al reported that reversion of previously acquired resistance is associated with the onset of EMT in CCRCC with sunitinib resistance. ${ }^{67}$ Induction of genes associated with EMT may also concurrently activate the signaling responsible for therapy resistance in the tumor microenvironment. The return to an epithelial phenotype with sensitivity to cancer therapy in metastatic RCC has been demonstrated in human tumor xenografts. ${ }^{68}$

\section{MECHANISM OF ACTION OF EXISTING THERAPIES FOR RENAL CELL CARCINOMA}

As mentioned previously, RCCs are highly vascularized cancers. VEGF and mTOR are two key signaling pathways of interest in RCC therapeutics. RCC may be characterized by the silent mutation of the VHL gene. ${ }^{69,70} \mathrm{pVHL}$ is a component of the E3 ubiquitin ligase complex, which is a protagonist in proteasome-mediated degradation of $\mathrm{HIF} \alpha{ }^{70} \mathrm{HIF} \alpha$ is a transcription factor and when unregulated results in the transcription of a wide range of genes including VEGF, PDGF, and transforming growth factor alpha $(\mathrm{TGF}-\alpha) .{ }^{70}$ These genes are crucial for tumor angiogenesis and progression. Existing targeted therapies are directed toward specific gene products, whereas drug resistance involves a different set of gene targets. ${ }^{71}$ Sorafenib is a commonly used small molecule TKI, but sunitinib is the most common first-line therapy. ${ }^{72}$ They both act as an antagonist of VEGFR and PDGFR and attenuate tumor angiogenesis. VEGFR and PDGFR inhibition is relevant only in VHL-inactivated modes of RCC. ${ }^{73}$ Several other VEGF pathway inhibitors have proven to reduce tumor mass in more than $80 \%$ of patients with RCC. ${ }^{74-76}$ In a preclinical model, such a reduction of tumor mass suggests heterogeneity of RCC in which hypoxia may be responsible for tumor growth rather than loss or alteration of the VHL gene. ${ }^{75}$ mTOR pathway activation involves a growth factor signal transduction and several intercellular regulatory factors. ${ }^{77}$ Activation of the mTOR pathway triggers enhanced synthesis of ribosomes that increases translation of mRNA to protein. ${ }^{44}$ These effects lead to the production of HIF1 $\alpha$, as well as cell cycle regulators such as cMyc and cyclin D1. ${ }^{77}$ Current first- and second-line targeted therapies for RCC are listed in Table 2 with their molecular targets. ${ }^{78-89}$

\section{NOVEL THERAPEUTIC AGENTS FOR RENAL CELL CARCINOMA Angiopoietins (Trebananib)}

Ang-1/2, ligands for the endothelial receptors Tie1 and Tie2, may be critical for blood vessel maturation and integrity. Key roles are basal angiogenesis in response to hypoxia in RCC and vascular stability in VEGF blockade. ${ }^{90}$ In human tumor xenograft mouse models, combined Ang-2 and VEGF-A inhibition had a synergistic antitumor activity. ${ }^{11}$ The combination of trebananib, an anti-Ang peptibody (peptide-Fc fusion protein), and VEGFR TKls has had mixed outcomes in the treatment of patients with advanced RCC. For example, in a phase II randomized trial in advanced RCC, trebananib and sorafenib in combination had a better therapeutic response than placebo ( $38 \%$ vs $25 \%$, respectively). However, no significant effect on median progression-free survival (PFS) was seen. ${ }^{92}$ Patients in the placebo arm, when switched to sorafenib plus trebananib at $10 \mathrm{mg} / \mathrm{kg}$ weekly, had an overall response rate of only $3 \%$. These results indicate the inability of trebananib to overcome acquired resistance to sorafenib. In a similar study, PFS was improved with a combination of sunitinib and trebananib. ${ }^{93}$ No normal tissue toxicity was recorded for trebananib in the study. A trebananib-sunitinib combination had relatively more benefits than trebananib-sorafenib, possibly because of the 
Table 2. Current Targeted Therapies for Renal Cell Carcinoma

\begin{tabular}{|c|c|c|c|c|}
\hline Drug & Indication & $\begin{array}{l}\text { Median Overall } \\
\text { Survival, months }\end{array}$ & $\begin{array}{l}\text { Median Progression-Free } \\
\text { Survival, months }\end{array}$ & Targets \\
\hline Sunitinib 78,79 & First line & 26.4 & 11.0 & VEGFR, PDGFR, FLT3, c-KIT, CSF1R, RET \\
\hline Sorafenib ${ }^{80}$ & Second line & 19.3 & 5.5 & VEGFR, PDGFR, RAF \\
\hline Pazopanib 81 & First and second line & 22.9 & 11.1 & VEGFR, FLT3, c-KIT, PDGFR \\
\hline Everolimus $^{82}$ & Second line & 14.8 & 4.0 & mTOR, HIF1, VEGF \\
\hline Temsirolimus $^{83}$ & First line & 10.9 & 3.8 & mTOR, HIF1, HIF2, VEGF \\
\hline Axitinib 84 & Second line & 21.7 & 10.1 & VEGFR, PDGFR, c-KIT \\
\hline \multicolumn{5}{|l|}{ Bevacizumab +} \\
\hline interferon alpha ${ }^{85}$ & First line & 18.3 & 10.2 & VEGF \\
\hline Cabozantinib $^{86}$ & Second line & 21.4 & 7.4 & RET, KIT, AXL, FLT3, c-MET, VEGFR \\
\hline Dovitinib 87 & Second line & 9.7 & 3.6 & FGFR, VEGFR, PDGFR \\
\hline Nivolumab 88,99 & Second line & 23.4 & $2.7-4.2$ & PD-1 \\
\hline Lenvatinib 89 & Second line & 18.4 & 7.4 & VEGFR, PDGFR, FGFR, RET, c-KIT \\
\hline
\end{tabular}

AXL, receptor tyrosine kinase; c-KIT, tyrosine-protein kinase; c-MET, tyrosine-protein kinase met; CSF1R, colony-stimulating factor 1 receptor; FGFR, fibroblast growth factor receptor; FLT3, fms-like tyrosine kinase 3; HGF, hepatocyte growth factor; HIF1/2, hypoxia-inducible factor 1/2; IFN- $\alpha$, interferon alpha; KIT, proto-oncogene; mTOR, mammalian target of rapamycin; mTORC1, mammalian target of rapamycin complex 1; PD-1, programmed death protein 1; PDGF, platelet-derived growth factor; PDGFR, platelet-derived growth factor receptor; RAF, rapidly accelerated fibrosarcoma; RET, protooncogene rearranged during transfection; VEGF, vascular endothelial growth factor; VEGFR, vascular endothelial growth factor receptor.

potent VEGF inhibition of sunitinib, which may maximize the Ang inhibition on tumor angiogenesis.

\section{c-Met and Hepatocyte Growth Factor (Cabozantinib)}

c-Met (sometimes termed Met or MET) is a receptor tyrosine kinase that when bound to its ligand hepatocyte growth factor (HGF) activates a wide range of different cellular signaling pathways, including those involved in proliferation, motility, migration, and invasion. ${ }^{94}$ High tumor grade and clinical stage in RCC correlate with increased c-Met expression, which is also considered an independent predictor of poor prognosis in patients with RCC. ${ }^{94}$ Expression of c-Met was higher in endothelial cells than in tumor cells in a human tumor xenograft model. This rationale provides an explanation for the development of resistance to VEGF-targeted therapy by maintaining alternate angiogenic pathways. ${ }^{95}$ In tumors resistant to the VEGF pathway inhibitor, expression of HGF, the ligand for $c-M e t$, was increased. The increase in the c-Met/HGF pathway is believed to be one of the drivers for acquired resistance to antiangiogenic therapy. Selective c-Met inhibitors in combination with sunitinib may act to decrease resistance to therapy in RCC. ${ }^{96}$ Cabozantinib (XL184) is a multikinase inhibitor that, in addition to inhibiting the Met receptor and VEGFR2, also inhibits several other potentially relevant tyrosine kinases receptors, namely RET (rearranged during transfection tyrosine-protein kinase), KIT (otherwise mast/stem cell growth factor receptor), AXL (cell surface receptor tyrosine kinase), and FLT3 (fms-like tyrosine kinase-3). ${ }^{97}$ Cabozantinib has been approved for the treatment of several cancers, including advanced metastatic RCC. In a clinical study, 25 previously treated patients with metastatic RCC were administered a $140 \mathrm{mg}$ daily dose of cabozantinib. Twenty-eight percent of patients (7 patients) had a partial response, while $52 \%$ of patients (13 patients) had their disease stabilized. ${ }^{97}$ The median PFS was 14.7 months, higher than for treatment-naïve patients. An effective response was observed in 3 of 4 patients with bone metastasis, while 2 patients had effective palliation of bone pain.

These results led to randomized phase II and then phase III trials of sunitinib and everolimus (mTOR inhibitor), respectively. Several other c-Met receptor inhibitors and HGF or cMet antibodies are under clinical investigation. ${ }^{98}$ The potential of these agents - as single agents and in combination with other VEGF-targeted therapy - to treat advanced RCC is encouraging. Papillary RCC, an aggressive subtype of $\mathrm{RCC}$, often has c-Met mutations, making it a prime therapy target. Figure 3 summarizes the vessel normalization in tumors in response to antiangiogenesis therapy and tumor regrowth and dissemination.

\section{Immunotherapeutics}

One of the recently understood mechanisms associated with the progression of RCC is the immune checkpoint pathway which consists of cellular interactions that prevent excessive activation of T cells under normal conditions. ${ }^{99}$ As an evasion mechanism, many tumors are able to stimulate the expression of immune checkpoint molecules, resulting in a phenotype of exhausted T cells that cannot restrain tumor progression. ${ }^{100}$ One inhibitory ligand and receptor that are important immune checkpoint modulators in solid tumors are the programmed death ligand 1 (PD-L1), also called B7$\mathrm{H} 1$ or CD274, and the programmed death protein 1 (PD-1), also called CD279. This pair prevents the killing of cancer cells by cytotoxic T lymphocytes. ${ }^{101}$ PD-1 is expressed by activated T cells among other cells, while PD-L1 is overexpressed on many tumor types including RCC. ${ }^{101}$

RCCs are established as immunogenic tumors because of the high level of tumor $T$ cell infiltration and responsiveness to new immunotherapies. ${ }^{102}$ Additionally, because RCCs 


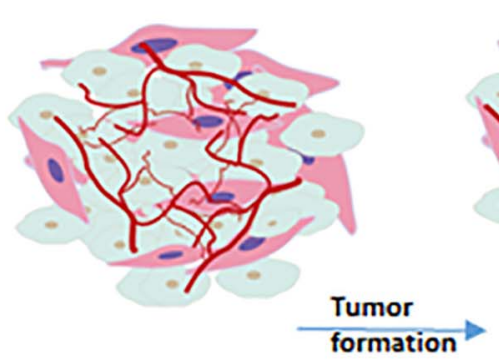

Normal
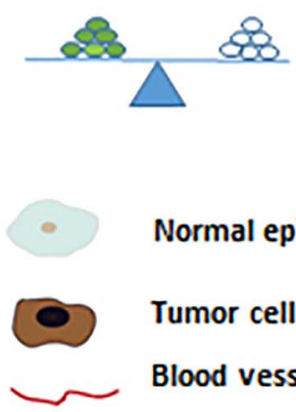

Normal epithelial cell

Tumor cell

Blood vessel

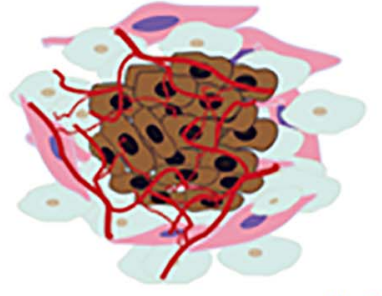

Antiangiogenesis therapy
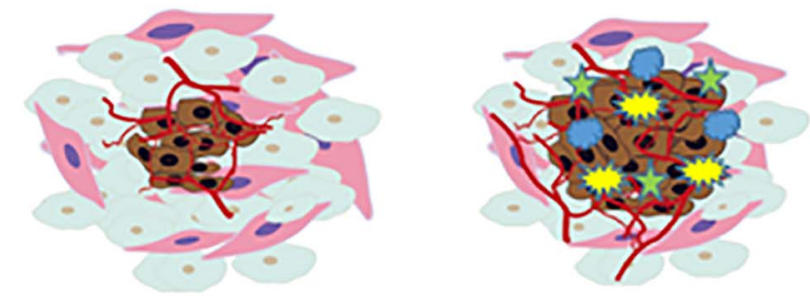

Recurrence of angiogenesis

Abnormal

Normalized

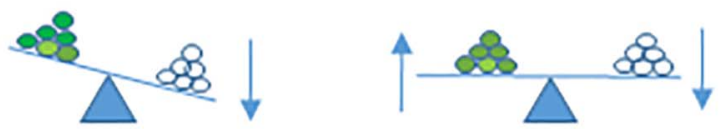

$\infty$ Antiangiogenesis factors

$\infty$ Proangiogenesis factors

Bone marrow-derived cells
Abnormal

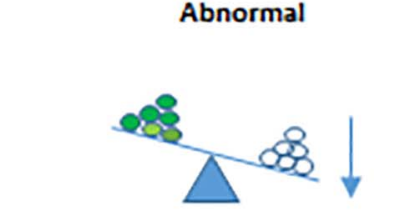

\section{(}

Figure 3. Model of vessel normalization in tumors in response to antiangiogenesis therapy: tumor regrowth and dissemination. In normal tissues, the actions of antiangiogenic factors counterbalance the actions of proangiogenic factors. Under pathologic conditions, the increased expression of proangiogenic factors and the reduced antiangiogenic factors deregulate this balance, predominant in the case of tumors with a very abnormal vasculature. In response to antiangiogenic therapy, the balance of antiangiogenesis and proangiogenesis is brought back to near normal, and tissue vasculature normalization is observed. Initially, the treatment inhibits the growth of the primary tumor, but the growth inhibition is generally followed by tumor relapse because of gradual development of resistance to therapy.

develop resistance to chronic use of targeted TKIs, immune checkpoint blockade has become a point of interest. ${ }^{103}$ The rationale is to restore the patient's natural tumor-specific $T$ cell-mediated immune responses by neutralizing any inhibitory signaling. ${ }^{103}$ Nivolumab, a PD-1 monoclonal antibody approved for patients with metastatic melanoma and lung cancers, has also been approved for use in metastatic RCC. ${ }^{88,104}$ Nivolumab neutralizes the interaction between PD-1 and its ligands PD-L1 and PD-L2. ${ }^{88}$ PD-1 interaction with its ligands is normally responsible for the downregulation of cellular immune response. ${ }^{105}$ Nivolumab has been shown to enhance $\mathrm{T}$ cell function in vitro and can play a vital role in antitumor activity. ${ }^{105}$ In clinical studies, treating patients who have metastatic RCC with nivolumab was safe and effective. ${ }^{106}$ Sunitinib-nivolumab and pazopanibnivolumab combinations are being tested in patients with advanced metastatic RCC. ${ }^{107}$

Initial clinical studies of nivolumab in patients with advanced ccRCC demonstrated important clinical activity and provided the rationale for a phase III trial. ${ }^{108}$ In this clinical trial, called CheckMate 025, previously treated patients with advanced RCC were randomized to nivolumab vs everolimus. The nivolumab group not only had increased overall survival but also health-related quality of life benefits. ${ }^{104,109}$ However, the response rate in the nivolumab group was $24 \%$ partial and only $1 \%$ complete. The expression of PD-L1 on tumor cells was not associated with overall survival. Another phase III clinical trial was the ARISER study. In one of the researchers' publications, the combination therapy of nivolumab and ipilimumab, an anti-cytotoxic $\mathrm{T}$ lymphocyte-associated protein 4 (CTLA-4) checkpoint inhibitor, was used with previously untreated patients with advanced RCC and markedly improved patient response rate compared with sunitinib in intermediate- or poor-risk disease and PD-L1 expression of $\geq 1 \%$ in tumors. ${ }^{110}$

Patient outcome and decisions made for application of new therapies are not always positive for immunotherapies. Treatment with tivozanib (a selective inhibitor of VEGFR 1, 2 , and 3) after sorafenib in patients with advanced RCC demonstrated antitumor activity and was associated with few serious patient adverse events, but the drug did not receive US Food and Drug Administration approval for use in patients with RCC. ${ }^{111}$ In another of the publications from the ARISER clinical trial, adjuvant weekly treatment with girentuximab, a monoclonal antibody that binds CAIX, had no clinical benefit for high-risk RCC patients following nephrectomy. ${ }^{112}$ In the ASSURE trial testing adjuvant therapy with sunitinib or sorafenib against placebo, patients with high-risk ccRCC did not have significantly improved outcomes. ${ }^{113,114}$

In comparison with some nonspecific immunotherapiesfor example, the cytokines IL-2 and IFN- $\alpha$-next-generation targeted immunotherapeutics enable the induction of a more specific T cell response against RCC cells. One example is IL-8. Induction of IL-8 preserved the angiogenic response 
in HIF1 $\alpha$-deficient colon cancer cells, and application of IL-8 neutralizing antibody decreased angiogenesis. ${ }^{51}$ In a mouse xenograft model of RCC, tumor growth in sunitinibresistant mice was significantly reduced with IL-8 neutralization compared to mice on sunitinib treatment alone. In an additional analysis in this report, higher IL-8 expression was observed in patients with ccRCC who had intrinsic/preexisting resistance to sunitinib, suggesting that early resistance to VEGFR TKIs could be augmented by preexisting elevated expression of IL-8. ${ }^{52}$ In a phase III trial of pazopanib for patients with advanced RCC, higher expression of IL-8 correlated with shorter PFS. MiR-200 microRNA inhibited tumor angiogenesis by targeting IL-8 and CXCL1 secreted by tumor cells and the endothelium. ${ }^{115}$ These studies show that inhibiting IL-8, either directly or indirectly, has therapeutic potential in patients with resistant RCC. IL-6 is also associated with poor prognosis in RCC. ${ }^{116}$ Tocilizumab, an IL-6 receptor inhibitor, has been tested preclinically in cell cultures and in mice after TKI resistance developed to sorafenib, sunitinib, and pazopanib. ${ }^{116}$ IL-6 neutralization by tocilizumab resulted in reduced tumor cell proliferation. Thus, a combination therapy of TKIs and IL-6 receptor inhibitors may represent a novel therapeutic approach for RCC treatment. The toxicity to noncancer tissue remains to be fully evaluated.

\section{CONCLUSION}

A clinically significant issue for treatment of RCC, particularly metastatic RCC, is its development of resistance to targeted therapies. The initial tumor stabilization or regression induced by VEGF and/or mTOR pathway inhibition is not sustained. Current evidence has proven a correlation between the reestablishment of angiogenesis and resistance to VEGF inhibition. However, these mechanisms are unable to provide clear and unique insights into the resistance mechanisms that can be used to design new therapeutics. Data from preclinical and clinical studies investigating the efficacy of dose increase or alternate (relatively more potent) inhibitors of the VEGF pathway support the rationale that the VEGF pathway is a critical target. However, resistance inevitably occurs and develops even with more potent agents that are used as second- and third-line therapies. Available treatments for metastatic RCC are continuously being proposed, particularly in high-risk patients with clinically localized disease. The trials produce mixed outcomes for patients. The mTOR pathway is central to cancer cell growth deregulation, and mTOR inhibitors therefore add some overlapping but novel pathways for consideration. Targeted immunotherapeutics are certainly an attractive alternative or adjunct therapy to the antiangiogenic compounds, and they are in constant development. The outcomes for patients with advanced RCC will, therefore, be greatly improved with enhanced, more potent, and multitargeted signaling pathway inhibition, including immune checkpoint blockade.

\section{ACKNOWLEDGMENTS}

The research program was partially supported by educational and research grants provided by the Saudi Arabia Cultural Mission and The University of Queensland-Ochsner research seed funds. Otherwise, the authors have no financial or proprietary interest in the subject matter of this article.

\section{REFERENCES}

1. Siegel RL, Miller KD, Jemal A. Cancer statistics, 2017. CA Cancer J Clin. 2017 Jan;67(1):7-30. doi: 10.3322/caac.21387.

2. Porta C, Sabbatini R, Procopio G, Paglino C, Galligioni E, Ortega $C$. Primary resistance to tyrosine kinase inhibitors in patients with advanced renal cell carcinoma: state-of-the-science. Expert Rev Anticancer Ther. 2012 Dec;12(12):1571-1577. doi: 10.1586/era.12.81.

3. Takyar S, Diaz J, Sehgal M, Sapunar F, Pandha H. First-line therapy for treatment-naive patients with advanced/metastatic renal cell carcinoma: a systematic review of published randomized controlled trials. Anticancer Drugs. 2016 Jun;27(5):383-397. doi: $10.1097 / C A D .0000000000000335$.

4. Kanesvaran R, Tan MH. Targeted therapy for renal cell carcinoma: the next lap. J Carcinog. 2014 Feb 20;13:3. doi: 10.4103/1477-3163.127638.

5. Duran I, Lambea J, Maroto P, et al. Resistance to targeted therapies in renal cancer: the importance of changing the mechanism of action. Target Oncol. 2017 Feb;12(1): 19-35. doi: 10.1007/s11523-016-0463-4.

6. Piva F, Giulietti M, Santoni M, et al. Epithelial to mesenchymal transition in renal cell carcinoma: implications for cancer therapy. Mol Diagn Ther. 2016 Apr;20(2):111-117. doi: 10.1007/s40291-016-0192-5.

7. Ferlay J, Soerjomataram I, Dikshit R, et al. Cancer incidence and mortality worldwide: sources, methods and major patterns in GLOBOCAN 2012. Int J Cancer. 2015 Mar 1;136(5):E359-E386. doi: 10.1002/ijc.29210.

8. Lotan Y, Karam JA, Shariat SF, et al. Renal cell carcinoma risk estimates based on participants in the prostate, lung, colorectal, and ovarian cancer screening trial and national lung screening trial. Urol Oncol. 2016 Apr;34(4):167.e9-167.e16. doi: 10.1016/j.urolonc.2015.10.011.

9. Znaor A, Lortet-Tieulent J, Laversanne M, Jemal A, Bray F. International variations and trends in renal cell carcinoma incidence and mortality. Eur Urol. 2015 Mar;67(3):519-530. doi: 10.1016/j.eururo.2014.10.002.

10. Muglia VF, Prando A. Renal cell carcinoma: histological classification and correlation with imaging findings. Radiol Bras. 2015 May-Jun;48(3):166-174. doi: 10.1590/0100-3984.2013.1927.

11. Haake SM, Rathmell WK. Renal cancer subtypes: should we be lumping or splitting for therapeutic decision making? Cancer. 2017 Jan 1;123(2):200-209. doi: 10.1002/cncr.30314.

12. Samaratunga $H$, Gianduzzo T, Delahunt B. The ISUP system of staging, grading and classification of renal cell neoplasia. $J$ Kidney Cancer VHL. 2014 Jul 20;1(3):26-39. doi: 10.15586/jkcvhl.2014.11.

13. Varshney N, Kebede AA, Owusu-Dapaah H, Lather J, Kaushik M, Bhullar JS. A review of Von Hippel-Lindau syndrome. J Kidney Cancer VHL. 2017 Aug 2;4(3):20-29. doi: 10.15586/jkcvhl.2017.88.

14. Hashimoto T, Shibasaki F. Hypoxia-inducible factor as an angiogenic master switch. Front Pediatr. 2015 Apr 24;3:33. doi: 10.3389/fped.2015.00033.

15. McCarty G, Awad O, Loeb DM. WT1 protein directly regulates expression of vascular endothelial growth factor and is a mediator of tumor response to hypoxia. J Biol Chem. 2011 Dec 23;286(51):43634-43643. doi: 10.1074/jbc.M111.310128.

16. Que WC, Qiu HQ, Cheng Y, Liu MB, Wu CY. PTEN in kidney cancer: a review and meta-analysis. Clin Chim Acta. 2018 May;480:92-98. doi: 10.1016/j.cca.2018.01.031. 
17. Girgin C, Tarhan H, Hekimgil M, Sezer A, Gürel G. P53 mutations and other prognostic factors of renal cell carcinoma. Urol Int. 2001;66(2):78-83. doi: $10.1159 / 000056575$.

18. Razafijatovo CF, Stiehl D, Deininger E, Rechsteiner M, Moch $H$, Schraml P. VHL missense mutations in the p53 binding domain show different effects on $\mathrm{p} 53$ signaling and $\mathrm{HIF} \alpha$ degradation in clear cell renal cell carcinoma. Oncotarget. 2017 Feb 7;8(6):10199-10212. doi: 10.18632/oncotarget.14372.

19. Juengel E, Kim D, Makarević J, et al. Molecular analysis of sunitinib resistant renal cell carcinoma cells after sequential treatment with RAD001 (everolimus) or sorafenib. J Cell Mol Med. 2015;19(2):430-441.

20. Semenza GL. Targeting HIF-1 for cancer therapy. Nat Rev Cancer. 2003 Oct;3(10):721-732. doi: 10.1038/nrc1187.

21. Morris MR, Hughes DJ, Tian YM, et al. Mutation analysis of hypoxia-inducible factors HIF1A and HIF2A in renal cell carcinoma. Anticancer Res. 2009 Nov;29(11):4337-4343.

22. Shen C, Kaelin WG Jr. The VHL/HIF axis in clear cell renal carcinoma. Semin Cancer Biol. 2013 Feb;23(1):18-25. doi: 10.1016/j.semcancer.2012.06.001.

23. Wettersten HI, Aboud OA, Lara PN Jr, Weiss RH. Metabolic reprogramming in clear cell renal cell carcinoma. Nat Rev Nephrol. 2017 Jul;13(7):410-419. doi: 10.1038/nrneph.2017.59.

24. Hamanaka RB, Chandel NS. Targeting glucose metabolism for cancer therapy. J Exp Med. 2012 Feb 13;209(2):211-215. doi: 10.1084/jem.20120162.

25. Warburg O. On the origin of cancer cells. Science. 1956 Feb 24;123(3191):309-314.

26. Vander Heiden MG, Cantley LC, Thompson CB. Understanding the Warburg effect: the metabolic requirements of cell proliferation. Science. 2009 May 22;324(5930):1029-1033. doi: 10.1126/science.1160809.

27. Parks SK, Chiche J, Pouyssegur J. pH control mechanisms of tumor survival and growth. J Cell Physiol. 2011 Feb;226(2):299-308. doi: 10.1002/jcp.22400.

28. Bedke J, Gouttefangeas $C$, Singh-Jasuja H, Stevanović S, Behnes CL, Stenzl A. Targeted therapy in renal cell carcinoma: moving from molecular agents to specific immunotherapy. World J Urol. 2014 Feb;32(1):31-38. doi: 10.1007/s00345-013-1033-3.

29. Santoni M, Massari F, Amantini C, et al. Emerging role of tumor-associated macrophages as a therapeutic targets in patients with metastatic renal cell carcinoma. Cancer Immunol Immunother. 2013 Dec;62(12):1757-1768. doi: 10.1007/s00262-013-1487-6.

30. Bedke J, Chun FK, Merseburger A, et al. Inflammatory prognostic markers in clear cell renal cell carcinomapreoperative $C$-reactive protein does not improve predictive accuracy. BJU Int. 2012 Dec;110(11 Pt B):E771-E777. doi: 10.1111/j.1464-410X.2012.11642.x.

31. Andersen R, Westergaard MCW, Kjeldsen JW, et al. T-cell responses in the microenvironment of primary renal cell carcinoma-implications for adoptive cell therapy. Cancer Immunol Res. 2018 Feb;6(2):222-235. doi: 10.1158/2326-6066.CIR-17-0467.

32. Tannir N, Hammers H, Amin A. First-line vascular endothelial growth factor targeted therapy in renal cell carcinoma: priming the tumor microenvironment for immunotherapy. Curr Med Res Opin. 2018 May;34(5):825-831. doi: 10.1080/03007995.2018.1423960.

33. Takahashi A, Sasaki H, Kim SJ, et al. Markedly increased amounts of messenger RNAs for vascular endothelial growth factor and placenta growth factor in renal cell carcinoma associated with angiogenesis. Cancer Res. 1994 Aug 1;54(15):4233-4237.

34. Geevarghese A, Herman IM. Pericyte-endothelial crosstalk: implications and opportunities for advanced cellular therapies. Transl Res. 2014 Apr;163(4):296-306. doi: 10.1016/j.trsl.2014.01.011.

35. Erber R, Thurnher A, Katsen AD, et al. Combined inhibition of VEGF and PDGF signaling enforces tumor vessel regression by interfering with pericyte-mediated endothelial cell survival mechanisms. FASEB J. 2004 Feb;18(2):338-340. doi: 10.1096/fj.03-0271fje.

36. Currie MJ, Gunningham SP, Turner K, et al. Expression of the angiopoietins and their receptor Tie2 in human renal clear cell carcinomas; regulation by the von Hippel-Lindau gene and hypoxia. J Pathol. 2002 Dec;198(4):502-510. doi: 10.1002/path.1228.

37. Ghidini M, Petrelli F, Ghidini A, et al. Clinical development of mTOR inhibitors for renal cancer. Expert Opin Investig Drugs. 2017 Nov;26(11):1229-1237. doi: $10.1080 / 13543784.2017 .1384813$.

38. Saxton RA, Sabatini DM. mTOR signaling in growth, metabolism, and disease. Cell. 2017 Mar 9;168(6):960-976. doi: 10.1016/j.cell.2017.02.004.

39. Xu Q, Krause M, Samoylenko A, Vainio S. Wnt signaling in renal cell carcinoma. Cancers (Basel). 2016 Jun 17;8(6). doi: $10.3390 /$ cancers8060057.

40. Inoki K, Ouyang H, Zhu T, et al. TSC2 integrates Wnt and energy signals via a coordinated phosphorylation by AMPK and GSK3 to regulate cell growth. Cell. 2006 Sep 8;126(5):955-968. doi: 10.1016/j.cell.2006.06.055.

41. Janssens $N$, Janicot M, Perera T. The Wnt-dependent signaling pathways as target in oncology drug discovery. Invest New Drugs. 2006 Jul;24(4):263-280. doi: $10.1007 / \mathrm{s} 10637-005-5199-4$.

42. Busch J, Seidel C, Kempkensteffen C, et al. Sequence therapy in patients with metastatic renal cell carcinoma: comparison of common targeted treatment options following failure of receptor tyrosine kinase inhibitors. Eur Urol. 2011 Dec;60(6):1163-1170. doi: 10.1016/j.eururo.2011.07.037.

43. Park K, Lee JL, Park I, et al. Comparative efficacy of vascular endothelial growth factor (VEGF) tyrosine kinase inhibitor (TKI) and mammalian target of rapamycin (mTOR) inhibitor as second-line therapy in patients with metastatic renal cell carcinoma after the failure of first-line VEGF TKI. Med Oncol. 2012 Dec;29(5):3291-3297. doi: 10.1007/s12032-012-0227-7.

44. Bergers $G$, Hanahan D. Modes of resistance to anti-angiogenic therapy. Nat Rev Cancer. 2008 Aug;8(8):592-603. doi: $10.1038 / \mathrm{nrc} 2442$.

45. Kelderman S, Schumacher TN, Haanen JB. Acquired and intrinsic resistance in cancer immunotherapy. Mol Oncol. 2014 Sep 12;8(6):1132-1139. doi: 10.1016/j.molonc.2014.07.011.

46. Gotink KJ, Broxterman HJ, Labots M, et al. Lysosomal sequestration of sunitinib: a novel mechanism of drug resistance. Clin Cancer Res. 2011 Dec 1;17(23):7337-7346. doi: 10.1158/1078-0432.CCR-11-1667.

47. Kuczynski EA, Sargent DJ, Grothey A, Kerbel RS. Drug rechallenge and treatment beyond progression-implications for drug resistance. Nat Rev Clin Oncol. 2013 Oct; 10(10):571-587. doi: 10.1038/nrclinonc.2013.158.

48. Diekstra MH, Fritsch A, Kanefendt F, et al. Population modeling integrating pharmacokinetics, pharmacodynamics, pharmacogenetics, and clinical outcome in patients with 
sunitinib-treated cancer. CPT Pharmacometrics Syst Pharmacol. 2017 Sep;6(9):604-613. doi: 10.1002/psp4.12210.

49. Bhatt RS, Atkins MB. Molecular pathways: can activin-like kinase pathway inhibition enhance the limited efficacy of VEGF inhibitors? Clin Cancer Res. 2014 Jun 1;20(11):2838-2845. doi: 10.1158/1078-0432.CCR-13-2788.

50. Casanovas O, Hicklin DJ, Bergers G, Hanahan D. Drug resistance by evasion of antiangiogenic targeting of VEGF signaling in late-stage pancreatic islet tumors. Cancer Cell. 2005 Oct;8(4):299-309. doi: 10.1016/j.ccr.2005.09.005.

51. Mizukami Y, Jo WS, Duerr EM, et al. Induction of interleukin-8 preserves the angiogenic response in HIF- $1 \alpha$-deficient colon cancer cells. Nat Med. 2005 Sep;11(9):992-997. doi: $10.1038 / \mathrm{nm} 1294$.

52. Huang D, Ding Y, Zhou M, et al. Interleukin-8 mediates resistance to antiangiogenic agent sunitinib in renal cell carcinoma. Cancer Res. 2010 Feb 1;70(3):1063-1071. doi: 10.1158/0008-5472.CAN-09-3965.

53. Wang $X$, Bullock $A J$, Zhang $L$, et al. The role of angiopoietins as potential therapeutic targets in renal cell carcinoma. Transl Oncol. 2014 Apr;7(2):188-195. doi: 10.1016/j.tranon.2014.02.003.

54. Huang $\mathrm{H}$, Lai JY, Do J, et al. Specifically targeting angiopoietin-2 inhibits angiogenesis, Tie2-expressing monocyte infiltration, and tumor growth. Clin Cancer Res. 2011 Mar 1;17(5):1001-1011. doi: 10.1158/1078-0432.CCR-10-2317.

55. Stukalin I, Alimohamed N, Heng DY. Contemporary treatment of metastatic renal cell carcinoma. Oncol Rev. $2016 \mathrm{Jul}$ 1;10(1):295. doi: 10.4081/oncol.2016.295.

56. Song M. Recent developments in small molecule therapies for renal cell carcinoma. Eur J Med Chem. 2017 Dec 15;142:383-392. doi: 10.1016/j.ejmech.2017.08.007.

57. Pollard JW. Tumour-educated macrophages promote tumour progression and metastasis. Nat Rev Cancer. 2004 Jan;4(1):71-78. doi: 10.1038/nrc1256.

58. Hattori K, Heissig B, Wu Y, et al. Placental growth factor reconstitutes hematopoiesis by recruiting VEGFR1(+) stem cells from bone-marrow microenvironment. Nat Med. 2002 Aug;8(8):841-849. doi: 10.1038/nm740.

59. De Palma M, Venneri MA, Galli R, et al. Tie2 identifies a hematopoietic lineage of proangiogenic monocytes required for tumor vessel formation and a mesenchymal population of pericyte progenitors. Cancer Cell. 2005 Sep;8(3):211-226. doi: 10.1016/j.ccr.2005.08.002.

60. Bunt SK, Sinha P, Clements VK, Leips J, Ostrand-Rosenberg S. Inflammation induces myeloid-derived suppressor cells that facilitate tumor progression. J Immunol. $2006 \mathrm{Jan}$ 1;176(1):284-290.

61. Du R, Lu KV, Petritsch C, et al. HIF1 $\alpha$ induces the recruitment of bone marrow-derived vascular modulatory cells to regulate tumor angiogenesis and invasion. Cancer Cell. 2008 Mar;13(3):206-220. doi: 10.1016/j.ccr.2008.01.034.

62. Xin H, Zhang C, Herrmann A, Du Y, Figlin R, Yu H. Sunitinib inhibition of Stat 3 induces renal cell carcinoma tumor cell apoptosis and reduces immunosuppressive cells. Cancer Res. 2009 Mar 15;69(6):2506-2513. doi: 10.1158/0008-5472.CAN-08-4323.

63. Zhitomirsky B, Assaraf YG. Lysosomes as mediators of drug resistance in cancer. Drug Resist Updat. 2016 Jan;24:23-33. doi: 10.1016/j.drup.2015.11.004.

64. Joosten SC, Hamming L, Soetekouw PM, et al. Resistance to sunitinib in renal cell carcinoma: from molecular mechanisms to predictive markers and future perspectives. Biochim
Biophys Acta. 2015 Jan;1855(1):1-16. doi: 10.1016/j.bbcan.2014.11.002.

65. Giuliano S, Cormerais Y, Dufies M, et al. Resistance to sunitinib in renal clear cell carcinoma results from sequestration in lysosomes and inhibition of the autophagic flux. Autophagy. 2015;11(10):1891-1904. doi: 10.1080/15548627.2015.1085742.

66. Blouw B, Song H, Tihan T, et al. The hypoxic response of tumors is dependent on their microenvironment. Cancer Cell. 2003 Aug;4(2):133-146.

67. Hammers HJ, Verheul HM, Salumbides B, et al. Reversible epithelial to mesenchymal transition and acquired resistance to sunitinib in patients with renal cell carcinoma: evidence from a xenograft study. Mol Cancer Ther. 2010 Jun;9(6):1525-1535. doi: 10.1158/1535-7163.MCT-09-1106.

68. Singla M, Bhattacharyya S. Autophagy as a potential therapeutic target during epithelial to mesenchymal transition in renal cell carcinoma: an in vitro study. Biomed Pharmacother. 2017 Oct;94:332-340. doi: 10.1016/j.biopha.2017.07.070.

69. Clifford SC, Prowse AH, Affara NA, Buys CH, Maher ER. Inactivation of the von Hippel-Lindau (VHL) tumour suppressor gene and allelic losses at chromosome arm 3p in primary renal cell carcinoma: evidence for a VHLindependent pathway in clear cell renal tumourigenesis. Genes Chromosomes Cancer. 1998 Jul;22(3):200-209.

70. Kourembanas S, Hannan RL, Faller DV. Oxygen tension regulates the expression of the platelet-derived growth factor-B chain gene in human endothelial cells. J Clin Invest. 1990 Aug;86(2):670-674. doi: 10.1172/JCl114759.

71. Choueiri TK, Motzer RJ. Systemic therapy for metastatic renal-cell carcinoma. N Engl J Med. 2017 Jan 26;376(4):354-366. doi: 10.1056/NEJMra1601333.

72. Mendel DB, Laird AD, Xin X, et al. In vivo antitumor activity of SU11248, a novel tyrosine kinase inhibitor targeting vascular endothelial growth factor and platelet-derived growth factor receptors: determination of a pharmacokinetic/pharmacodynamic relationship. Clin Cancer Res. 2003 Jan;9(1):327-337.

73. Bielecka ZF, Malinowska A, Brodaczewska KK, et al. Hypoxic $3 \mathrm{D}$ in vitro culture models reveal distinct resistance processes to TKIs in renal cancer cells. Cell Biosci. 2017 Dec 16;7:71. doi: 10.1186/s13578-017-0197-8.

74. Wilhelm SM, Carter WC, Tang L, et al. BAY 43-9006 exhibits broad spectrum oral antitumor activity and targets the RAF/MEK/ERK pathway and receptor tyrosine kinases involved in tumor progression and angiogenesis. Cancer Res. 2004 Oct 1;64(19):7099-7109. doi: 10.1158/0008-5472.CAN-04-1443.

75. Schor-Bardach R, Alsop DC, Pedrosa I, et al. Does arterial spin-labeling MR imaging-measured tumor perfusion correlate with renal cell cancer response to antiangiogenic therapy in a mouse model? Radiology. 2009 Jun;251(3):731-742. doi: 10.1148/radiol.2521081059.

76. Gomes AP, Blenis J. A nexus for cellular homeostasis: the interplay between metabolic and signal transduction pathways. Curr Opin Biotechnol. 2015 Aug;34:110-117. doi: 10.1016/j.copbio.2014.12.007.

77. Vadlakonda L, Pasupuleti M, Pallu R. Role of PI3K-AKT-mTOR and Wnt signaling pathways in transition of G1-S phase of cell cycle in cancer cells. Front Oncol. 2013 Apr 12;3:85. doi: 10.3389/fonc.2013.00085.

78. Ko JS, Zea AH, Rini Bl, et al. Sunitinib mediates reversal of myeloid-derived suppressor cell accumulation in renal cell 
carcinoma patients. Clin Cancer Res. 2009 Mar

15;15(6):2148-2157. doi: 10.1158/1078-0432.CCR-08-1332.

79. Motzer RJ, Hutson TE, Tomczak $P$, et al. Overall survival and updated results for sunitinib compared with interferon alfa in patients with metastatic renal cell carcinoma. J Clin Oncol. 2009 Aug 1;27(22):3584-3590. doi: 10.1200/JCO.2008.20.1293.

80. Escudier B, Eisen T, Stadler WM, et al. Sorafenib in advanced clear-cell renal-cell carcinoma. New Engl J Med. 2007 Jan 11;356(2):125-134. doi: 10.1056/NEJMoa060655.

81. Gupta S, Spiess PE. The prospects of pazopanib in advanced renal cell carcinoma. Ther Adv Urol. 2013 Oct;5(5):223-232. doi: $10.1177 / 1756287213495099$.

82. Buti S, Leonetti A, Dallatomasina A, Bersanelli M. Everolimus in the management of metastatic renal cell carcinoma: an evidence-based review of its place in therapy. Core Evid. 2016 Sep 1;11:23-36. doi: 10.2147/CE.S98687.

83. Otto T, Eimer C, Gerullis H. Temsirolimus in renal cell carcinoma. Transplant Proc. 2008 Dec;40(10 Suppl):S36-S39. doi: 10.1016/j.transproceed.2008.10.006.

84. Hutson TE, Al-Shukri S, Stus VP, et al. Axitinib versus sorafenib in first-line metastatic renal cell carcinoma: overall survival from a randomized phase III trial. Clin Genitourin Cancer. 2017 Feb;15(1):72-76. doi: 10.1016/j.clgc.2016.05.008.

85. Harshman LC, Srinivas S. The bevacizumab experience in advanced renal cell carcinoma. Onco Targets Ther. 2010 Oct 5;3:179-189.

86. Singh H, Brave M, Beaver JA, et al. U.S. Food and Drug Administration approval: cabozantinib for the treatment of advanced renal cell carcinoma. Clin Cancer Res. 2017 Jan 15;23(2):330-335. doi: 10.1158/1078-0432.CCR-16-1073.

87. Kang YK, Yoo C, Ryoo BY, et al. Phase Il study of dovitinib in patients with metastatic and/or unresectable gastrointestinal stromal tumours after failure of imatinib and sunitinib. $\mathrm{Br} J$ Cancer. 2013 Oct 29;109(9):2309-2315. doi: $10.1038 /$ bjc.2013.594.

88. Farolfi A, Schepisi G, Conteduca V, Burgio SL, Lolli C, De Giorgi U. Pharmacokinetics, pharmacodynamics and clinical efficacy of nivolumab in the treatment of metastatic renal cell carcinoma. Expert Opin Drug Metab Toxicol. 2016 Sep;12(9):1089-1096. doi: 10.1080/17425255.2016.1214713.

89. Kuznar W. Lenvatinib extends survival in metastatic renal-cell carcinoma. Am Health Drug Benefits. 2015 Aug;8(Spec Issue): 18.

90. Yamakawa M, Liu LX, Belanger AJ, et al. Expression of angiopoietins in renal epithelial and clear cell carcinoma cells: regulation by hypoxia and participation in angiogenesis. Am J Physiol Renal Physiol. 2004 Oct;287(4):F649-F657. doi: 10.1152/ajprenal.00028.2004.

91. Kienast Y, Klein C, Scheuer W, et al. Ang-2-VEGF-A CrossMab, a novel bispecific human IgG1 antibody blocking VEGF-A and Ang-2 functions simultaneously, mediates potent antitumor, antiangiogenic, and antimetastatic efficacy. Clin Cancer Res. 2013 Dec 15;19(24):6730-6740. doi: 10.1158/1078-0432.CCR-13-0081.

92. Rini B, Szczylik C, Tannir NM, et al. AMG 386 in combination with sorafenib in patients with metastatic clear cell carcinoma of the kidney: a randomized, double-blind, placebo-controlled, phase 2 study. Cancer. 2012 Dec 15;118(24):6152-6161. doi: 10.1002/cncr.27632.

93. van Meeteren LA, Thorikay M, Bergqvist $S$, et al. Anti-human activin receptor-like kinase 1 (ALK1) antibody attenuates bone morphogenetic protein 9 (BMP9)-induced ALK1 signaling and interferes with endothelial cell sprouting. J Biol Chem. 2012 May 25;287(22):18551-18561. doi: 10.1074/jbc.M111.338103.
94. Gibney GT, Aziz SA, Camp RL, et al. c-Met is a prognostic marker and potential therapeutic target in clear cell renal cell carcinoma. Ann Oncol. 2013 Feb;24(2):343-349. doi: 10.1093/annonc/mds463.

95. Shojaei F, Lee JH, Simmons BH, et al. HGF/c-Met acts as an alternative angiogenic pathway in sunitinib-resistant tumors. Cancer Res. 2010 Dec 15;70(24):10090-10100. doi: 10.1158/0008-5472.CAN-10-0489.

96. Bersanelli M, Buti S. Cabozantinib in metastatic renal cell carcinoma: latest findings and clinical potential. Ther Adv Med Oncol. 2017 Oct;9(10):627-636. doi: $10.1177 / 1758834017724314$.

97. Choueiri TK, Escudier B, Powles T, et al. Cabozantinib versus everolimus in advanced renal-cell carcinoma. N Engl J Med. 2015 Nov 5;373(19):1814-1823. doi: 10.1056/NEJMoa1510016.

98. Eder JP, Vande Woude GF, Boerner SA, LoRusso PM. Novel therapeutic inhibitors of the c-Met signaling pathway in cancer. Clin Cancer Res. 2009 Apr 1;15(7):2207-2214. doi: 10.1158/1078-0432.CCR-08-1306.

99. Mazza C, Escudier B, Albiges L. Nivolumab in renal cell carcinoma: latest evidence and clinical potential. Ther Adv Med Oncol. 2017 Mar;9(3):171-181. doi: 10.1177/1758834016679942.

100. Ascierto PA, Addeo R, Cartenì G, et al. The role of immunotherapy in solid tumors: report from the Campania Society of Oncology Immunotherapy (SCITO) meeting, Naples 2014. J Transl Med. 2014 Oct 21;12:291. doi: 10.1186/s12967-014-0291-1.

101. Barata PC, Ornstein MC, Garcia JA. The evolving treatment landscape of advanced renal cell carcinoma in patients progressing after VEGF inhibition. J Kidney Cancer VHL. 2017 May 11;4(2):10-18. doi: 10.15586/jkcvhl.2017.69.

102. Janssen $L M E$, Ramsay EE, Logsdon CD, et al. The immune system in cancer metastasis: friend or foe? J Immunother Cancer. 2017;5(1):79. doi: 10.1186/s40425-017-0283-9.

103. Topalian SL, Hodi FS, Brahmer JR, et al. Safety, activity, and immune correlates of anti-PD-1 antibody in cancer. N Engl J Med. 2012 Jun 28;366(26):2443-2454. doi: $10.1056 /$ NEJMoa1200690.

104. Escudier B, Sharma P, McDermott DF, et al; CheckMate 025 investigators. CheckMate 025 randomized phase 3 study: outcomes by key baseline factors and prior therapy for nivolumab versus everolimus in advanced renal cell carcinoma. Eur Urol. 2017 Dec;72(6):962-971. doi: 10.1016/j.eururo.2017.02.010.

105. Kuusk T, Albiges L, Escudier B, et al. Antiangiogenic therapy combined with immune checkpoint blockade in renal cancer. Angiogenesis. 2017 May;20(2):205-215. doi: 10.1007/s10456-017-9550-0.

106. McDermott DF, Drake CG, Sznol M, et al. Survival, durable response, and long-term safety in patients with previously treated advanced renal cell carcinoma receiving nivolumab. $J$ Clin Oncol. 2015 Jun 20;33(18):2013-2020. doi: $10.1200 / J C O .2014 .58 .1041$.

107. Motzer RJ, Rini BI, McDermott DF, et al. Nivolumab for metastatic renal cell carcinoma: results of a randomized phase II trial. J Clin Oncol. 2015 May 1;33(13):1430-1437. doi: 10.1200/JCO.2014.59.0703.

108. Motzer RJ, Escudier B, McDermott DF, et al. Nivolumab versus everolimus in advanced renal-cell carcinoma. N EnglJ Med. 2015 Nov 5;373(19):1803-1813. doi: 10.1056/NEJMoa1510665.

109. Cella D, Grünwald V, Nathan P, et al. Quality of life in patients with advanced renal cell carcinoma given nivolumab versus 
everolimus in CheckMate 025: a randomised, open-label, phase 3 trial. Lancet Oncol. 2016 Jul;17(7):994-1003. doi: 10.1016/S1470-2045 (16)30125-5.

110. Motzer RJ, Tannir NM, McDermott DF, et al; CheckMate 214 Investigators. Nivolumab plus ipilimumab versus sunitinib in advanced renal-cell carcinoma. N Engl J Med. $2018 \mathrm{Apr}$ 5;378(14):1277-1290. doi: 10.1056/NEJMoa1712126.

111. Molina AM, Hutson TE, Nosov D, et al. Efficacy of tivozanib after sorafenib in patients with advanced renal cell carcinoma: crossover of a phase 3 study. Eur J Cancer. 2018 May;94:87-94. doi: 10.1016/j.ejca.2018.02.009.

112. Chamie K, Donin NM, Klöpfer P, et al. Adjuvant weekly girentuximab following nephrectomy for high-risk renal cell carcinoma: the ARISER randomized clinical trial. JAMA Oncol. 2017 Jul 1;3(7):913-920. doi: 10.1001/jamaoncol.2016.4419.
113. Patel DN, Figlin RA, Kim HL. Adjuvant treatment for renal cell carcinoma: do we finally have a major breakthrough? Clin Adv Hematol Oncol. 2016 Nov;14(11):907-914.

114. Haas NB, Manola J, Dutcher JP, et al. Adjuvant treatment for high-risk clear cell renal cell cancer: updated results of a high-risk subset of the ASSURE randomized trial. JAMA Oncol. 2017 Sep 1;3(9):1249-1252. doi: 10.1001/jamaoncol.2017.0076.

115. Pecot CV, Rupaimoole $R$, Yang $D$, et al. Tumour angiogenesis regulation by the miR-200 family. Nat Commun. 2013;4:2427. doi: $10.1038 /$ ncomms3427.

116. Ishibashi K, Haber T, Breuksch I, et al. Overriding TKI resistance of renal cell carcinoma by combination therapy with IL-6 receptor blockade. Oncotarget. $2017 \mathrm{Jul}$

21;8(33):55230-55245. doi: 10.18632/oncotarget.19420.

This article meets the Accreditation Council for Graduate Medical Education and the American Board of Medical Specialties Maintenance of Certification competencies for Patient Care and Medical Knowledge. 